\title{
Sporophytic self-incompatibility in Senecio squalidus (Asteraceae): $S$ allele dominance interactions and modifiers of cross-compatibility and selfing rates
}

\author{
AC Brennan ${ }^{1}$, DA Tabah ${ }^{2}$, SA Harris ${ }^{3}$ and SJ Hiscock ${ }^{2}$ \\ ${ }^{1}$ School of Biology, University of St Andrews, Fife, UK; ${ }^{2}$ School of Biological Sciences, University of Bristol, Bristol, UK and \\ ${ }^{3}$ Department of Plant Sciences, University of Oxford, Oxford, UK
}

\begin{abstract}
Understanding genetic mechanisms of self-incompatibility (SI) and how they evolve is central to understanding the mating behaviour of most outbreeding angiosperms. Sporophytic SI (SSI) is controlled by a single multi-allelic locus, $S$, which is expressed in the diploid (sporophyte) plant to determine the SI phenotype of its haploid (gametophyte) pollen. This allows complex patterns of independent $S$ allele dominance interactions in male (pollen) and female (pistil) reproductive tissues. Senecio squalidus is a useful model for studying the genetic regulation and evolution of SSI because of its population history as an alien invasive species in the UK. $S$. squalidus maintains a small number of $S$ alleles (7-11) with a high frequency of dominance interactions. Some $S$. squalidus individuals also show partial selfing and/or greater levels of cross-compatibility than expected
\end{abstract}

under SSI. We previously speculated that these might be adaptations to invasiveness. Here we describe a detailed characterization of the regulation of $\mathrm{SSI}$ in $S$. squalidus. Controlled crosses were used to determine the $S$ allele dominance hierarchy of six $S$ alleles and effects of modifiers on cross-compatibility and partial selfing. Complex dominance interactions among $S$ alleles were found with at least three levels of dominance and tissue-specific codominance. Evidence for $S$ gene modifiers that increase selfing and/or cross-compatibility was also found. These empirical findings are discussed in the context of theoretical predictions for maintenance of $S$ allele dominance interactions, and the role of modifier loci in the evolution of SI.

Heredity (2011) 106, 113-123; doi:10.1038/hdy.2010.29; published online 7 April 2010

Keywords: sporophytic self-incompatibility; $S$ allele; dominance; modifier locus; pseudo-self-compatibility

\section{Introduction}

Understanding mechanisms of self-incompatibility (SI), where self- or self-related pollen is recognized and specifically inhibited by the female pistil, is key to understanding the mating behaviour of many flowering plants (Hiscock and McInnis, 2003). Most SI systems typically have simple genetic control based on a single multi-allelic locus $(S)$. The $S$ locus usually consists of one pistil-expressed $S$ gene (female determinant) and one pollen-expressed $S$ gene (male determinant) that form a non-recombining $S$ haplotype (hereafter referred to as an 'S allele'). Pistil and pollen products from the same $S$ allele recognize each other and interact specifically to initiate the pollen inhibition response that prevents fertilization (Hiscock and McInnis, 2003). Polymorphism at the $S$ locus is maintained by strong negative frequency-dependent selection, which favours new or rare $S$ alleles because they are compatible with a greater proportion of the potential mates in a population (Schierup, 1998).

Self-incompatibility systems fall into two major classes: gametophytic self-incompatibility (GSI), in

Correspondence: Professor SJ Hiscock, School of Biological Sciences, University of Bristol, Woodland Road, Bristol BS8 1UG, UK.

E-mail: simon.hiscock@bristol.ac.uk

Received 17 February 2009; revised 27 November 2009; accepted 17 December 2009; published online 7 April 2010 which the $S$ phenotype of the pollen (male gametophyte) is determined by its own haploid $S$ genotype, and sporophytic self-incompatibility (SSI), in which the pollen $S$ phenotype is determined by the diploid $S$ genotype of its parent plant (sporophyte) (Hiscock and McInnis, 2003). A major consequence of this difference in pollen expression is that GSI requires strict codominance between $S$ alleles in the pistil to prevent heterozygous individuals being compatible with half their own (self) pollen. No such constraints apply to SSI in which complex $S$ allele dominance interactions are possible in both pollen and pistil, thereby introducing an additional level of mating system complexity relative to GSI (Schierup et al., 1997). Within SSI systems, different kind of dominance interactions are possible, including complete dominance and tissue-specific dominance, and $S$ alleles can often be ranked into a dominance hierarchy consisting of dominance classes of $S$ alleles with codominant interactions between alleles within the group and dominance interactions between alleles from different groups (for example, Ockendon, 1974; Kowyama et al., 1994; Mehlenbacher, 1997; Glemin et al., 2005). $S$ alleles that are frequently recessive in $S$ allele interactions (hereafter referred to as recessive $S$ alleles) are subject to less intense negative frequencydependent selection than dominant or codominant $S$ alleles leading to a 'recessive effect' whereby recessive $S$ alleles are more frequent within populations than more dominant $S$ alleles (Sampson, 1974; Schierup, 1998; 
Billiard et al., 2007). There are many other subtle consequences of asymmetric negative frequency-dependent selection on $S$ alleles with differing dominance interactions including: increased effective migration rate between populations, shorter long-term evolutionary persistence and greater linked genetic load for dominant alleles relative to more recessive alleles (Schierup et al., 1997; Stone, 2004; Billiard et al., 2007).

It appears that the different SSI systems for which $S$ allele dominance interactions have been studied are subject to different functional constraints regarding possible $S$ allele dominance interactions. For example, in the well-studied Brassica (Brassicaceae) SSI system, $S$ allele dominance in the pistil appears to be limited to two or three dominance levels, whereas in pollen, there are multiple dominance levels (Ockendon, 1974; Glemin et al., 2005). In contrast many largely coincident dominance levels have been observed for both pollen and pistil $S$ alleles in other SSI systems within the Brassicaceae and other plant families such as the Convolvulaceae and Betulaceae (Kowyama et al., 1994; Mehlenbacher, 1997; Prigoda et al., 2005; Schierup et al., 2006). These differences may be a consequence of different molecular mechanisms of SSI in these groups of plants (Hiscock and McInnis, 2003). The various $S$ allele dominance characteristics of different SSI systems are important to consider because theoretical models reveal that $S$ allele dominance has a large effect on mating dynamics and the evolution of SSI systems (Schierup et al., 1997; Uyenoyama, 2000; Billiard et al., 2007).

Recently, insights into the mechanism of $S$ allele dominance have begun to emerge from studies in the Brassicaceae. Surprisingly, $S$ allele dominance appears to be regulated differently in pistil and in pollen. In pollen, $S$ allele dominance is controlled at the transcription (mRNA) level (Shiba et al., 2002), whereas in the pistil it is controlled at the post-transcriptional (protein) level (Hatakeyama et al., 2001). This goes some way to explaining the tissue-specific differences in dominance classes apparent for Brassica SSI and suggests that transcriptional regulation of pollen $S$ allele dominance could facilitate switches between $S$ allele dominance classes. Currently, little is known about the mechanism of control of $S$ allele dominance in other independent SSI systems. It is possible that, where constraints permit, $S$ allele dominance interactions can respond rapidly to selection so as to optimize SSI-mediated reproduction. For example, evolution towards increasing $S$ allele dominance is predicted under certain conditions (Schierup et al., 1997; Vekemans et al., 1998; Pannell et al., 2005) and a possible association has been noted between the frequency of $S$ allele dominance interactions and total $S$ allele number based on studies of SSI in wild populations (Brennan et al., 2003).

Despite the deceptively simple genetics of SI systems, based on control by one or a few $S$ loci, it is becoming increasingly apparent from studies of natural populations that multiple other loci contribute to the regulation and expression of SI, such that SI is perhaps better viewed as a quantitative rather than a qualitative trait (Levin, 1996; Vogler and Kalisz, 2001; Goodwillie et al., 2005). In general, it seems that $S$-modifier loci are maintained as part of SI systems when they contribute to the regulation of outcrossing or compensate for conditions where the reproductive costs of full SI are high (Vallejo-Marín and Uyenoyama, 2004; Harder et al., 2007; Busch and Schoen, 2008).

For SI to persist, the overall reproductive benefits of enforcing outcrossing must outweigh the substantial cost of rejecting otherwise viable pollen, termed 'reproductive compensation' (Harder et al., 2007). Avoidance of inbreeding depression in the presence of a considerable accumulated genetic load is considered to be a major force for the maintenance of SI (Vallejo-Marín and Uyenoyama, 2004; Porcher and Lande, 2005). However, the relationship is not a simple one because genetic load is also itself responsive to selection and coevolves with mating system (Latta, 1994; Glemín et al., 2001). Ecological factors such as pollination biology, dispersal and number of reproductive opportunities also affect reproductive assurance, and are extremely important for the maintenance and evolution of SI systems, because they influence the selective advantage of outcrossing versus selfing (Harder et al., 2007; Busch and Schoen, 2008; Johnston et al., 2009). Against this background of interacting factors that introduce shifting costs and benefits of outcrossing, it is perhaps no surprise that loci that influence SI expression and cause limited selfing (hereafter referred to as 'S modifiers') appear to be an extremely common feature of SI systems (Levin, 1996).

A common quantitative feature of SI systems is pseudo-self-compatibility (PSC), in which genetic and environmental factors cause variation in the strength of SI leading to low levels of self-fertilization but with seed set levels typically less than fully compatible crosspollinations (Levin, 1996). Loci responsible for PSC can have subtle and probably adaptive influences on SI expression, such as delayed acceptance of self-pollen in the absence of suitable cross-pollen-a form of intrafloral reproductive assurance (Vogler and Stephenson, 2001).

Modifiers of SI can also have distinct influences on SI expression in addition to relaxing the strength of the SI response and permitting some selfing. In particular, $S$ modifiers that alter cross-compatibility interactions without altering the selfing rate are noteworthy. The $G$ locus, observed to be acting subordinately to the $S$ locus, as part of the SSI system of many Brassicaceae species is the best studied example of this class of $S$ modifiers (Lewis et al., 1988; Zuberi and Lewis, 1988; Lewis, 1994). Alleles at the $G$ locus function to permit compatible crosses between individuals with the same $S$ allele that should otherwise be incompatible. This effect is only detectable in a subset of cross-interactions because compatible crosses based on $S$ genotypes take precedence over $G$ genotypes. The overall effect of the $G$ locus is to increase cross-compatibility over and above that expected for $S$ locus interactions alone. The $G$ locus, in contrast to the $S$ locus, appears to be under gametophytic control in pollen, leading to the suggestion that it represents the remnants of an ancestral GSI system in Brassicaceae that has largely been replaced by SSI (Lewis, 1994). Based on phylogenetic analyses of the distribution of SI systems, this evolutionary trajectory from GSI to SSI is likely to have occurred on multiple occasions during the radiation of angiosperms (Igic and Kohn, 2001).

Senecio squalidus is an important model for the study of SSI in the Asteraceae and mating system evolution more generally because its recent population history has been 
well documented and includes extreme population events that are likely to have had an impact on the behaviour of its SSI mating system. S. squalidus was introduced to Britain from Mount Etna (Sicily) about 300 years ago where it established itself in Oxford and eventually colonized most urban areas in Britain (James and Abbott, 2005). In contrast to predictions that an extreme population bottleneck and subsequent invasion should favour the breakdown of SI in favour of uniparental reproduction (Pannell and Barrett, 1998), S. squalidus shows a strong SSI system (Hiscock, 2000; Brennan et al., 2005). Nevertheless, the SSI system of S. squalidus does show features consistent with a recent population bottleneck, such as relatively few $S$ alleles compared with other wild SSI species, a high frequency of $S$ allele dominance interactions and some selfing due to the presence of PSC (Hiscock, 2000; Brennan et al., 2002, 2005, 2006). Both $S$ allele dominance and PSC increase cross-compatibility for a given number of $S$ alleles and have been proposed as a means by which the SSI system of invasive $S$. squalidus escapes the constraints of limited $S$ allele number (Brennan et al., 2002, 2003, 2006). Here we investigate the genetic regulation of the SSI system of S. squalidus in greater detail by characterizing $S$ allele dominance interactions more completely and exploring the expression and inheritance of partial selfing (PSC). We show that regulation of the SSI system of $S$. squalidus is complex with $S$ alleles showing at least three levels of dominance and tissue-specific codominance. We also find evidence for $S$ modifiers that increase rates of selfing and crosscompatibility between individuals. We discuss these findings in the context of recent theoretical models of the patterns and maintenance of $S$ allele dominance interactions and the role of $S$-modifier loci in SSI.

\section{Materials and methods}

\section{Plant material}

Progeny arrays were generated by performing controlled crosses between parental plants of known $S$ phenotype (that is, with one dominant $S$ allele identified) or known $S$ genotype (that is, both $S$ alleles identified) based on the results of previous controlled crossing experiments (Hiscock, 2000; Brennan et al., 2002). Plants of known $S$ phenotype included five individuals sampled directly from a wild Oxford population and assigned five different $S$ phenotypes based on diallel crossing studies (Brennan et al., 2002). These Ox individuals and their $S$ phenotypes were $\mathrm{O} \times 2=\mathrm{S}_{2} ; \mathrm{O} \times 4=\mathrm{S}_{3} ; \mathrm{O} \times 22=\mathrm{S}_{4}$; $\mathrm{O} \times 27=\mathrm{S}_{4} \mathrm{~S}_{5} \quad\left(S\right.$ genotype $\left.=S_{4} S_{5}\right)$ and Ox19= $\mathrm{S}_{6}$ (here referred to as; O2, O4, O22, O27 and O19 respectively). Other individuals with known homozygous $S$ genotype; OS-Bill-4, and A34-4-23 (here referred to as B4 and A23 respectively) were previously identified from controlled crossing studies of selfed progenies derived from individuals originally sampled from a different wild Oxford population (Hiscock, 2000). Crosses were therefore performed to cross-classify $S$ alleles identified in the two studies and cross-classified $S$ alleles then followed the nomenclature of Brennan et al. (2002). Thus the genotypes of B4 and A23 were identified as $S_{1} S_{1}$ and $S_{6} S_{6}$, respectively. The first set of progenies was derived from controlled crosses between $\mathrm{B} 4$ and each of $\mathrm{O} 2, \mathrm{O} 4$,
O22, 027 and O19. A second set of controlled cross progenies was derived from backcrosses between B4 $\times$ O19 progeny and one or both of their B4 and O19 parents. For each cross, there were only two to three parental $S$ alleles that produce a limited number of possible progeny $S$ phenotypes from which to deduce parental $S$ genotypes and dominance interactions. A third set of progeny arrays consisting entirely of $S_{1}$ or $S_{6}$ homozygous individuals were generated from controlled selfing of B4 and A23 individuals respectively. The $S$ homozygous selfed progeny diallels contained only a single $S$ allele and so permitted observation of the behaviour of $S$-modifier loci. Forced-selfing was performed according to Hiscock (2000) by applying selfing solution ( $1 \%$ salt, $0.1 \%$ Tween) to stigmas of bagged capitula with a fine brush, leaving to air-dry, then applying self-pollen from another capitulum from the same individual and re-bagging selfed capitula. Typically, 1-10 force-selfed fruits per capitulum are produced with this method so several capitula were force-selfed to obtain sufficient selfed fruits (Hiscock, 2000). Plants were grown from seed in a glasshouse in $10 \mathrm{~cm}$ or larger pots of loam-based compost with artificial lighting to achieve $16 \mathrm{~h}$ day length.

\section{Controlled crossing experiments}

Controlled self- and cross-pollinations, and classification of compatibility, based on fruit set, were performed as previously described in Hiscock (2000) and Brennan et al. (2002, 2006). Unless stated otherwise, crosses were progeny backcrosses to parents. In short, plants were prepared for crossing experiments by bagging branches bearing developing flower buds. The strength of SI was tested by counting the self-fruit set of at least six bagged flowering heads (capitula). Self-pollination was enhanced by occasional agitation of bagged capitula. SI was relied upon to prevent self-fruit set because emasculation of the many tiny florets of $S$. squalidus before crossing is impractical. A small number of individuals exhibited PSC producing a small number of self-fruits due to the presence of $S$ modifiers but compatible crosses could often still be identified among these PSC individuals because of their typically higher fruit-set. For controlled reciprocal cross-pollinations, capitula with open florets were gently brushed together and then individually bagged to prevent contamination with rogue pollen and to collect any resultant fruits as they ripened. Compatibility of crosses was classified by mean fruit-set per capitulum (fruit-set values) according to Brennan et al. (2002), that is, incompatible for values $0-2$, indeterminate for values $>2-10$ and compatible for values $>10$.

Incompatible backcrosses were interpreted as equivalent $S$ phenotypes and compatible backcrosses as different $S$ phenotypes. The compatibility and $S$ phenotypes of sample individuals were determined independently for each individual behaving as maternal or paternal parent to identify tissue-specific $S$ allele expression. Dominance interactions between $S$ alleles were identified by comparing the observed $S$ phenotypes with the limited number of expected $S$ genotypes for each cross progeny array. These progenies consisted of two identified $S$ alleles; $S_{1}$ from B4 and a dominant $S$ allele $\left(S_{\text {dom }}\right)$ from the Ox parent $(\mathrm{O} 2, \mathrm{O} 4, \mathrm{O} 22, \mathrm{O} 27$ or O19) and 


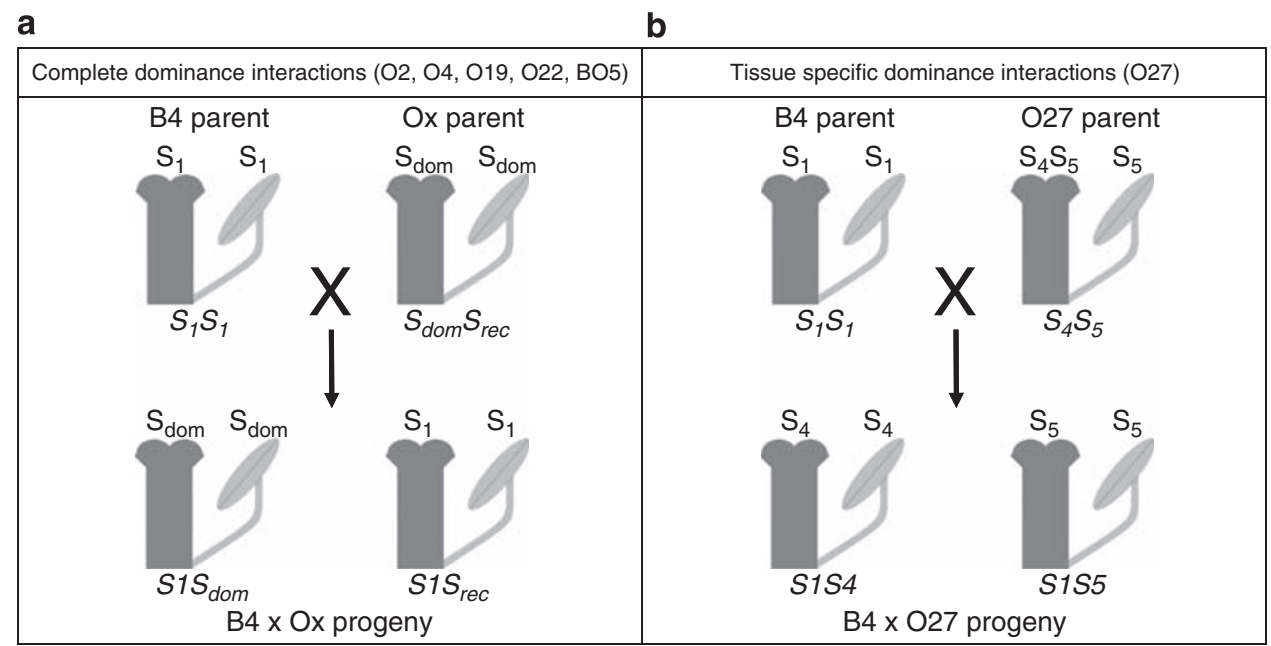

Figure 1 Parent-progeny crossing scheme used to test $S$ allele dominance interactions in the $\mathrm{B} 4 \times$ Ox progeny lines. Individuals' $S$ genotypes are placed below their respective 'flower' (pistil and stamen) images, whereas individuals' pistil and pollen S phenotypes are placed above their respective pistil and stamen images. The $S$ phenotypes of each progeny were determined by testing compatibility of backcrosses with $\mathrm{B} 4$ and their respective $\mathrm{O}(\mathrm{Ox})$ parents; the majority of $\mathrm{S}$ phenotypes were explained by the $S$ genotypes and dominance relationships described in the figure. Some progenies from the $\mathrm{B} 4 \times \mathrm{O} 19$ cross were also either weakly self-compatible or compatible for both parental backcrosses. (a) Progenies where the first parent, B4, had an $S_{1} S_{1}$ genotype (OS-Bill-4, Hiscock, 2000) and the other parent had an $S_{d o m} S_{\text {rec }}$ genotype $\left(\mathrm{O} 2, \mathrm{O} 4, \mathrm{O} 22\right.$ or O19; Brennan et al., 2002), where the $S_{\text {dom }}$ allele had previously been identified as $S_{2}, S_{3}, S_{4}$ or $S_{6}$ respectively. (b) A progeny where the first parent was B4 and the other parent had $S_{4} S_{5}$ genotype where $S_{5}$ was dominant over $S_{4}$ in pollen only (O27, Brennan et al., 2002).

one unidentified $S$ allele from the Ox parent that could be either $S_{1}, S_{d o m}$ or an unidentified recessive allele $\left(S_{\text {rec }}\right)$ (Figure 1). In the case of three parental $S$ alleles, dominance interactions were limited to one of $S_{\text {dom }}>S_{\text {rec }}>S_{1} ; S_{\text {dom }}>S_{1}>S_{\text {rec }}$; or $S_{1}>S_{\text {dom }}>S_{\text {rec }}$ or $S_{1}=S_{\text {dom }}>S_{\text {rec }}$, so there were a limited number of possible progeny $S$ phenotypes from which to deduce parental $S$ genotypes and dominance interactions (Figure 1). An overall dominance hierarchy between all $S$ alleles was constructed by grouping $S$ alleles into the minimum number of dominance levels necessary to explain the cross-incompatibility results from all backcross progenies. The dominance hierarchy was constructed independently for $S$ allele dominance interactions identified in pistil or pollen so as to account for tissue-specific dominance interactions.

Cross-compatibility results for the $\mathrm{B} 4 \times \mathrm{O} 19$ progeny array in particular were difficult to interpret under a single-locus model of $S$ allele dominance interactions. Thus, the dominance relationships of the $S$ alleles involved in this cross and the genetics of potential modifier loci were investigated further by growing up and performing parental and diallel crosses on progeny arrays consisting of second-generation B4O19 progeny back crossed with one or both B4 and O19 parents (Figure 2) and third-generation selfed B4 and A23 selfed lines.

\section{Results}

The majority of $S$ phenotypes for four out of five progeny arrays derived from $\mathrm{B} 4 \times \mathrm{Ox}$ crosses could be explained by simple models of $S$ allele dominance interactions (Figures 1 and 3; Table 1). Progeny arrays derived from B4 $\times$ Ox crosses with S phenotypes of S2, S3 and S4 (B4 crossed with $\mathrm{O} 2, \mathrm{O} 4$, and $\mathrm{O} 22$ respectively) all consisted of $S_{1}$ and parental $S$ phenotypes indicating that the $S_{2}, S_{3}$ and $S_{4}$ alleles interact dominantly with $S_{1}$. Furthermore, novel $S$ phenotypes were largely absent from these progeny arrays indicating that the Ox parents were either homozygous for their respective $S$ alleles or were heterozygous for an additional recessive $S$ allele that was either $S_{1}$ or recessive to $S_{1}$ (Figures 1 and 3; Table 1). The observed $S$ phenotypes of the $\mathrm{B} 4 \times \mathrm{O} 27$ progeny array could be explained by $S_{1}$ interacting recessively with $S_{4}$ and $S_{5}$, a pistil-specific codominance interaction between $S_{4}$ and $S_{5}$, and $S_{4}$ interacting recessively with $S_{5}$ in pollen (Figures $1 \mathrm{~b}$ and 3; Table 1). A minority of progeny individuals from these crosses showed additional $S$ phenotypes that could not be explained by these $S$ allele dominance interactions (Table 1; Figure 3). These $S$ phenotypes were probably the result of occasional cross failures in the case of incompatibility with both parents $\left(S_{1} S_{\text {dom }}\right.$ phenotypes, Table 1) as has been observed in previous $S$. squalidus crossing studies (for example, Brennan et al., 2006). Other progeny $S$ phenotypes that were compatible with both parents, particularly the $S$ phenotypes of the B4 $\times 019$ progeny array and B4O19 backcross arrays, were more difficult to interpret as part of a single-locus SSI model with fixed $S$ allele dominance interactions $\left(S_{\text {rec }}\right.$ phenotypes, Tables 1 and 2; Figures 2 and 4). This was because all $\mathrm{B} 4 \times \mathrm{O} 19$ progenies were either $S_{1}$ or a new unidentified $S$ phenotype, whereas the $S_{6}$ phenotype class should be present in at least half of the progenies given the dominant $S_{6}$ phenotype of the O19 parent (Figure 3). Nonetheless, the subsequent re-appearance and frequent occurrence of $S_{6}$ phenotypes among the $\mathrm{BO} 5 \times \mathrm{O} 19, \quad \mathrm{BO} 8 \times \mathrm{O} 19$ and $\mathrm{BO} 8 \times \mathrm{B} 4$ backcross progenies suggested that $S_{6}$ interacts dominantly with $S_{1}$ (Table 2; Figures 2 and 4).

The resulting $S$ allele dominance hierarchy constructed from the combined results from all progenies indicates that for the six $S$ alleles identified in the Oxford 
b

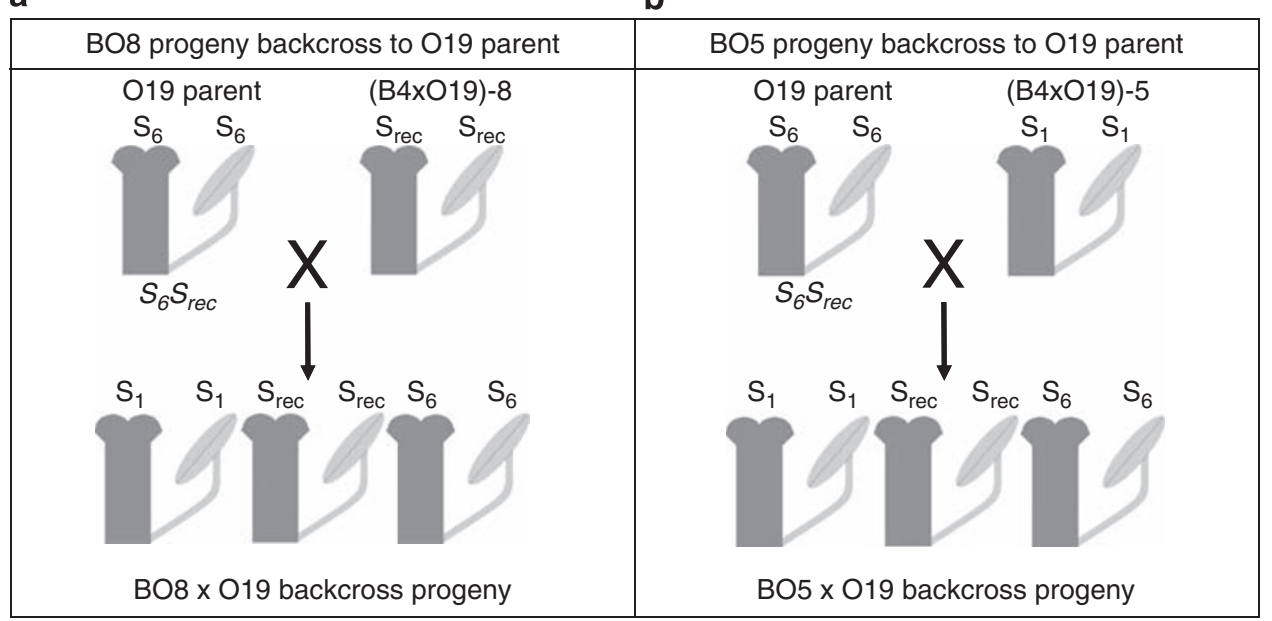

Figure 2 Parent-progeny backcrossing scheme to test $\mathrm{S}$ allele dominance interactions in the B4 $\times$ O19 backcrossed to O19 progeny lines. The $S$ genotypes and S phenotype labels follow the same scheme as Figure 1 . The $S$ genotypes below the pistil and stamen images have been omitted where crossing results did not permit conclusive identification. (a) A progeny where the first parent was O19 with an $S_{6} S_{r e c}$ genotype and the second parent was a B4 $\times$ O19 progeny individual, $(\mathrm{B} 4 \times \mathrm{O} 19)-8$, that was compatible with both parents. (b) A progeny where the first parent was O19 and the second parent was $(\mathrm{B} 4 \times \mathrm{O} 19)-5$ that was compatible with the O19 parent but not the B4 parent.

\begin{tabular}{|c|c|c|c|c|c|c|c|c|c|c|c|c|c|c|c|c|c|c|c|c|}
\hline Parent & & $\mathrm{O} 2$ & B4 & & & O4 & B4 & & & $\mathrm{O} 22$ & B4 & & & O27 & B4 & & & 019 & B4 & \\
\hline Geno. & & $S_{2} S_{r e c}$ & $S_{1} S_{1}$ & & & $S_{3} S_{r e c}$ & $S_{1} S_{1}$ & & & $S_{4} S_{r e c}$ & $S_{1} S_{1}$ & & & $S_{5} S_{4}$ & $S_{1} S_{1}$ & & & $S_{6} S_{r e c}$ & $S_{1} S_{1}$ & \\
\hline $\begin{array}{l}\text { Prog. } \\
\text { (mat) }\end{array}$ & Self & $\begin{array}{c}\mathrm{O} 2 \\
\text { (pat) }\end{array}$ & $\begin{array}{c}\text { B4 } \\
\text { (pat) }\end{array}$ & $S$ & Self & $\begin{array}{c}\text { O4 } \\
\text { (pat) }\end{array}$ & $\begin{array}{c}\text { B4 } \\
\text { (pat) }\end{array}$ & $S$ & Self & $\begin{array}{l}\mathrm{O} 22 \\
\text { (pat) }\end{array}$ & $\begin{array}{c}\text { B4 } \\
\text { (pat) }\end{array}$ & $S$ & Self & $\begin{array}{l}\text { O27 } \\
\text { (pat) }\end{array}$ & $\begin{array}{c}\text { B4 } \\
\text { (pat) }\end{array}$ & $S$ & Self & $\begin{array}{l}\text { O19 } \\
\text { (pat) }\end{array}$ & $\begin{array}{c}\text { B4 } \\
\text { (pat) }\end{array}$ & $S$ \\
\hline 1 & - & - & + & $\mathrm{S}_{2}$ & - & + & - & $S_{1}$ & - & - & + & $\mathrm{S}_{4}$ & - & - & + & $\mathrm{S}_{5}$ & - & + & $+/-$ & $\mathrm{S}_{\mathrm{rec}}$ ? \\
\hline 2 & - & - & + & $\mathrm{S}_{2}$ & - & + & - & $\mathrm{S}_{1}$ & - & + & $+/-$ & $\mathrm{S}_{1} ?$ & - & + & + & $\mathrm{S}_{\mathrm{rec}}$ & $+/-$ & + & + & $\mathrm{S}_{\mathrm{rec}}$ \\
\hline 3 & - & - & + & $\mathrm{S}_{2}$ & - & + & - & $S_{1}$ & - & + & - & $S_{1}$ & - & - & $+/-$ & $\mathrm{S}_{1} \mathrm{~S}_{5} ?$ & - & + & - & $\mathrm{S}_{1}$ \\
\hline 5 & - & + & - & $S_{1}$ & - & - & + & $\mathrm{S}_{3}$ & - & + & $+/-$ & $S_{1} ?$ & - & + & + & $\mathrm{S}_{\mathrm{rec}}$ & - & + & - & $S_{1}$ \\
\hline 6 & - & - & - & $\mathrm{S}_{1} \mathrm{~S}_{2}$ & - & + & - & $S_{1}$ & - & + & - & $S_{1}$ & - & + & + & $\mathrm{S}_{\mathrm{rec}}$ & - & + & - & $\mathrm{S}_{1}$ \\
\hline 7 & - & + & - & $\mathrm{S}_{1}$ & - & - & + & $\mathrm{S}_{3}$ & - & + & - & $S_{1}$ & - & - & + & $\mathrm{S}_{5}$ & - & + & + & $\mathrm{S}_{\mathrm{rec}}$ \\
\hline 8 & - & - & + & $\mathrm{S}_{2}$ & - & - & + & $\mathrm{S}_{3}$ & - & - & + & $\mathrm{S}_{4}$ & - & - & + & $\mathrm{S}_{5}$ & - & + & + & $\mathrm{S}_{\mathrm{rec}}$ \\
\hline 9 & - & - & + & $\mathrm{S}_{2}$ & - & - & + & $\mathrm{S}_{3}$ & - & - & + & $\mathrm{S}_{4}$ & - & + & + & $\mathrm{S}_{\mathrm{rec}}$ & - & + & $+/=$ & $\mathrm{S}_{\mathrm{rec}}$ ? \\
\hline 10 & - & + & $+1-$ & $\mathrm{S}_{1} ?$ & - & - & + & $\mathrm{S}_{3}$ & - & $+1-$ & + & $\mathrm{S}_{4} ?$ & - & - & + & $\mathrm{S}_{5}$ & $+/-$ & + & + & $\mathrm{S}_{\mathrm{rec}}$ \\
\hline 11 & - & + & - & $\mathrm{S}_{1}$ & - & + & $+1-$ & $\mathrm{S}_{1} ?$ & - & - & + & $\mathrm{S}_{4}$ & - & $+1-$ & + & $\mathrm{S}_{\mathrm{rec}} ?$ & - & + & - & $S_{1}$ \\
\hline $\begin{array}{l}\text { Prog. } \\
\text { (pat) }\end{array}$ & & $\begin{array}{c}\mathrm{O} 2 \\
\text { (mat) }\end{array}$ & $\begin{array}{c}\text { B4 } \\
\text { (mat) }\end{array}$ & $S$ & & $\begin{array}{c}\mathrm{O} 4 \\
\text { (mat) }\end{array}$ & $\begin{array}{c}\text { B4 } \\
\text { (mat) }\end{array}$ & $S$ & & $\begin{array}{c}\mathrm{O} 22 \\
\text { (mat) }\end{array}$ & $\begin{array}{c}\text { B4 } \\
\text { (mat) }\end{array}$ & $S$ & & $\begin{array}{l}\mathrm{O} 27 \\
\text { (mat) }\end{array}$ & $\begin{array}{c}\text { B4 } \\
\text { (mat) }\end{array}$ & $S$ & & $\begin{array}{c}019 \\
\text { (mat) }\end{array}$ & $\begin{array}{c}\text { B4 } \\
\text { (mat) }\end{array}$ & $S$ \\
\hline 1 & & \begin{tabular}{|l|}
- \\
\end{tabular} & + & $S_{2}$ & & \begin{tabular}{|l|}
+ \\
\end{tabular} & \begin{tabular}{|l|}
$+/-$ \\
\end{tabular} & $\mathrm{S}_{1} ?$ & & \begin{tabular}{|l|}
- \\
\end{tabular} & + & $\mathrm{S}_{4}$ & & \begin{tabular}{|l|}
- \\
\end{tabular} & + & $\mathrm{S}_{4} \mathrm{~S}_{5}$ & & + & $+/-$ & $\mathrm{S}_{\mathrm{rec}} ?$ \\
\hline 2 & & - & + & $\mathrm{S}_{2}$ & & $+/-$ & - & $\mathrm{S}_{1} ?$ & & + & - & $S_{1}$ & & $+/-$ & + & $\mathrm{S}_{4} \mathrm{~S}_{5} ?$ & & + & + & $\mathrm{S}_{\mathrm{rec}}$ \\
\hline 3 & & - & + & $\mathrm{S}_{2}$ & & + & - & $S_{1}$ & & + & - & $S_{1}$ & & $+/-$ & - & $S_{1} S_{5} ?$ & & + & - & $S_{1}$ \\
\hline 4 & & + & - & $S_{1}$ & & + & + & $\mathrm{S}_{\mathrm{rec}}$ & & + & - & $\mathrm{S}_{1}$ & & - & $+/-$ & $\mathrm{S}_{4} \mathrm{~S}_{5} ?$ & & + & + & $\mathrm{S}_{\mathrm{rec}}$ \\
\hline 5 & & + & - & $\mathrm{S}_{1}$ & & - & + & $\mathrm{S}_{3}$ & & + & - & $S_{1}$ & & - & + & $\mathrm{S}_{4} \mathrm{~S}_{5}$ & & + & - & $S_{1}$ \\
\hline 6 & & - & - & $\mathrm{S}_{1} \mathrm{~S}_{2}$ & & + & - & $S_{1}$ & & + & - & $S_{1}$ & & + & + & $\mathrm{S}_{\mathrm{rec}}$ & & + & - & $S_{1}$ \\
\hline 7 & & + & - & $\mathrm{S}_{1}$ & & - & + & $\mathrm{S}_{3}$ & & + & - & $S_{1}$ & & - & + & $\mathrm{S}_{4} \mathrm{~S}_{5}$ & & - & - & $S_{1} S_{6}$ \\
\hline 8 & & - & $+1-$ & $\mathrm{S}_{2} ?$ & & - & + & $\mathrm{S}_{3}$ & & $+1-$ & + & $\mathrm{S}_{4} ?$ & & - & + & $\mathrm{S}_{4} \mathrm{~S}_{5}$ & & + & + & $\mathrm{S}_{\mathrm{rec}}$ \\
\hline 9 & & - & + & $\mathrm{S}_{2}$ & & - & + & $\mathrm{S}_{3}$ & & $+/-$ & + & $\mathrm{S}_{4} ?$ & & - & + & $\mathrm{S}_{4} \mathrm{~S}_{5}$ & & - & - & $\mathrm{S}_{1} \mathrm{~S}_{6}$ \\
\hline 10 & & + & - & $\mathrm{S}_{1}$ & & - & + & $\mathrm{S}_{3}$ & & - & + & $\mathrm{S}_{4}$ & & - & + & $\mathrm{S}_{4} \mathrm{~S}_{5}$ & & $+/-$ & + & $\mathrm{S}_{\mathrm{rec}}$ ? \\
\hline 11 & & + & - & $S_{1}$ & & + & - & $S_{1}$ & & $+/-$ & + & $\mathrm{S}_{4} ?$ & & $+/-$ & + & $\mathrm{S}_{4} \mathrm{~S}_{5} ?$ & & + & - & $S_{1}$ \\
\hline 12 & & + & + & $\mathrm{S}_{\mathrm{rec}}$ & & - & + & $\mathrm{S}_{3}$ & & - & + & $\mathrm{S}_{4}$ & & + & + & $\mathrm{S}_{\mathrm{rec}}$ & & + & + & $\mathrm{S}_{\mathrm{rec}}$ \\
\hline
\end{tabular}

Figure 3 Self-incompatibility tests and backcross compatibility results for five Senecio squalidus progenies derived from a cross between an $S_{1} S_{1}$ genotype (B4) and individuals with $S$ phenotypes representing five additional $S$ alleles from an Oxford population (see legend to Figure 1). The top two rows list parental individuals and their genotypes for each cross. Genotypes marked ' $S_{\text {rec }}$ ' indicate an unidentified $S$ allele that is either recessive or equivalent to the other expressed allele in that individual. The boxed symbols are semi-diallels of cross results for backcrosses between progeny and parental individuals. Progenies are listed down the rows and selfings and parents are listed above their diallel cross results. Crosses with individuals acting as maternal and paternal are indicated by '(mat)' and '(pat)' respectively. Reciprocal cross results are placed in equivalent positions in the top and bottom rows of diallels for ease of comparison. Dark grey-shaded negatives indicate incompatible crosses with less than two fruits. Non-shaded pluses indicate compatible crosses with more than 10 fruits. Pale grey-shaded pluses and negatives indicate indeterminate crosses with 2-10 fruits. Observed progeny $S$ phenotypes are listed to the right of the diallels in the columns labelled ' $S$ '. Uncertain progeny $S$ phenotypes that included indeterminate crosses are marked with '?'; the $S$ phenotype decision for these progenies was made to coincide with the reciprocal maternal or paternal cross result or to minimize the number of different $S$ phenotypes in the progeny array. 
Table 1 Observed S phenotype frequencies for five S. squalidus progenies derived from a cross between an $S_{1} S_{1}$ genotype (B4) and individuals with $S$ phenotypes representing five additional $S$ alleles from an Oxford population

\begin{tabular}{|c|c|c|c|c|c|c|}
\hline \multirow[t]{2}{*}{ Progeny maternal S phenotype } & \multirow[t]{2}{*}{ Progeny paternal S phenotype } & \multicolumn{5}{|c|}{ Parents, (genotypes), allele dominance } \\
\hline & & $\begin{array}{c}\text { B4 O2 } \\
\left(\mathrm{S}_{1} \mathrm{~S}_{1}\right)\left(\mathrm{S}_{2} \mathrm{~S}_{\mathrm{rec}}\right) \\
\text { dom }=\mathrm{S}_{2}\end{array}$ & $\begin{array}{c}\text { B4 O4 } \\
\left(\mathrm{S}_{1} \mathrm{~S}_{1}\right)\left(\mathrm{S}_{3} \mathrm{~S}_{\mathrm{rec}}\right) \\
\text { dom }=\mathrm{S}_{3}\end{array}$ & $\begin{array}{c}\text { B4 O22 } \\
\left(\mathrm{S}_{1} \mathrm{~S}_{1}\right)\left(\mathrm{S}_{4} \mathrm{~S}_{\mathrm{rec}}\right) \\
\text { dom }=\mathrm{S} 4\end{array}$ & $\begin{array}{c}\text { B4 O27 } \\
\left(\mathrm{S}_{1} \mathrm{~S}_{1}\right)\left(\mathrm{S}_{5} \mathrm{~S}_{4}\right) \\
\operatorname{dom}=\mathrm{S}_{5} \text { rec }=\mathrm{S}_{4}\end{array}$ & $\begin{array}{c}\text { B4 O19 } \\
\left(\mathrm{S}_{1} \mathrm{~S}_{1}\right)\left(\mathrm{S}_{6} \mathrm{~S}_{\mathrm{rec}}\right. \\
\text { dom }=\mathrm{S}_{6}\end{array}$ \\
\hline S1 & S1 & 5 & 5 & 6 & 0 & 4 \\
\hline dom & dom & 5 & 6 & 6 & 4 & 0 \\
\hline rec & rec & 1 & 1 & 0 & 2 & 6 \\
\hline rec & dom & 0 & 0 & 0 & 5 & 0 \\
\hline S1dom & S1dom & 1 & 0 & 0 & 1 & 0 \\
\hline rec & S1dom & 0 & 0 & 0 & 0 & 2 \\
\hline
\end{tabular}

Except where stated otherwise, 'rec' indicates an S phenotype that is different from both parental S phenotypes and that has not been crossclassified against other $S$ alleles. Pale grey shaded frequencies signify the most common pair of $S$ phenotypes observed for each progeny array.

Table 2 Observed S phenotype frequencies for three $S$. squalidus progenies derived from backcrosses between a novel S phenotype B4 $\times$ O19 progeny (BO8) and its B4 and O19 parents and an $\mathrm{S}_{1}$ phenotype B4 $\times$ O19 progeny (BO5) and its O19 parent

\begin{tabular}{|c|c|c|c|c|}
\hline \multirow[t]{2}{*}{ Progeny maternal S phenotype } & \multirow[t]{2}{*}{ Progeny paternal S phenotype } & \multicolumn{3}{|c|}{ Parents, (genotypes), allele dominance } \\
\hline & & $\begin{array}{c}\text { B4 BO8 } \\
\left(\mathrm{S}_{1} \mathrm{~S}_{1}\right)\left(\mathrm{S}_{1} \mathrm{~S}_{6}\right)\end{array}$ & $\begin{array}{c}019 \text { BO8 } \\
\left(\mathrm{S}_{6} \mathrm{~S}_{\mathrm{rec}}\right)\left(\mathrm{S}_{1} \mathrm{~S}_{6}\right)\end{array}$ & $\begin{array}{rl}O 19 & B O 5 \\
\left(\mathrm{~S}_{6} \mathrm{~S}_{\mathrm{rec}}\right) & \left(\mathrm{S}_{1} \mathrm{~S}_{\mathrm{rec}}\right)\end{array}$ \\
\hline S1 & S1 & 6 & 3 & 2 \\
\hline S6 & S6 & 3 & 3 & 1 \\
\hline rec & rec & 0 & 2 & 5 \\
\hline S1 & rec & 0 & 0 & 2 \\
\hline S6 & rec & 0 & 0 & 1 \\
\hline rec & S1 & 0 & 1 & 0 \\
\hline S1S6 & S1S6 & 0 & 1 & 1 \\
\hline S6 & S1S6 & 0 & 2 & 0 \\
\hline
\end{tabular}

In each case, 'rec' indicates an unidentified S phenotype that is different from both parental S phenotypes and that has not been cross-classified against other $S$ alleles. Pale grey shaded frequencies signify the most common two or three $S$ phenotypes observed for each progeny array.

S. squalidus population, there are at least two dominance levels for alleles interacting in pistils and at least three dominance levels for alleles interacting in pollen (Figure 5). This dominance hierarchy represents a minimum estimate of the number of dominance classes for these $S$ alleles, because some $S$ alleles were conservatively grouped into the same dominance classes without having confirmed all $S$ allele codominance interactions within that class and because additional recessive alleles that could form part of the $S$ genotype of Ox parents that were not expressed in progeny were excluded (O2, O4, O22; Table 1; Figures 1 and 3). The pistil and pollen $S$ allele dominance hierarchies were identical for most $S$ alleles with the exception of an additional dominance level required to explain the pollen-specific dominance interaction observed between $S_{4}$ and $S_{5}$. Most dominance levels were represented by a single $S$ allele, with the exception of the most dominant $S$ allele dominance class assuming that this dominance class would not be broken up further by testing additional $S$ allele dominance interactions within the class.

In addition to elucidating $S$ allele dominance interactions in the Oxford S. squalidus population, the progeny array crossing experiments generated multiple lines of evidence for unlinked $S$-modifier alleles in some progeny lines. First, three of the twelve $\mathrm{B} 4 \times \mathrm{O} 19$ progenies and the $\mathrm{BO} 5 \times \mathrm{O} 19$ backcross progeny showed intermediate self-fruit set levels compared with the strongly expressed
SI of all of test individuals. Second, the $\mathrm{B} 4 \times \mathrm{O} 19$ progeny and the $\mathrm{BO} 5 \times \mathrm{O} 19$ and $\mathrm{BO} 8 \times \mathrm{O} 19$ backcross progenies consisted of compatible $S$ phenotypes that could not be explained by a simple single-locus SSI model with $S$ allele dominance interactions (Table 2; Figures 2 and 4). The $\mathrm{B} 4 \times \mathrm{O} 19$ progeny consisted of $\mathrm{S}$ phenotypes compatible with both parental $S$ phenotypes $\left(S_{\text {rec }}\right.$ in Table 1; Figure 1). This contradicts single-locus SSI model expectations because $S_{6}$ is dominant over the second recessive $S$ allele $\left(S_{\text {rec }}\right)$ in the O19 parent but is more recessive than $S_{1}$ relative to the $S_{r e c}$ allele in the $\mathrm{B} 4 \times \mathrm{O} 19$ progeny. Furthermore, under a single-locus SSI model, the B4O19.8 individual that was compatible with both parents would have had an $S_{1} S_{r e c}$ genotype but the B4O19.8 $\times$ B4 backcross progeny nonetheless contained $\mathrm{S}_{6}$ phenotypes (Table 2; Figures $2 \mathrm{~b}$ and 4 ). The remaining two B4O19 backcross progenies also contained more than two $S$ phenotypes that were poorly explained by a single-locus SSI model (Table 2; Figures 2 and 4). Finally, a crossing diallel between individuals from a forcedselfing of the $A 23 \mathrm{~S}_{6}$ individual revealed frequent crosscompatibilities between progeny individuals when no cross-compatibility was expected among such individuals because all were homozygous for the $S_{6}$ allele (Figure 6). Compatibility phenotypes within this array were complex and could not be grouped effectively, suggesting multi-locus control of cross-compatibility and segregation of allelic variants at these loci despite the inbred origin of the individuals. In each crossing 


\begin{tabular}{|c|c|c|c|c|c|c|c|c|c|c|c|c|c|c|c|}
\hline \multirow{2}{*}{\multicolumn{2}{|c|}{$\begin{array}{l}\text { Parent } \\
\text { Geno. }\end{array}$}} & \multirow{2}{*}{$\frac{\mathrm{BO} 8}{\mathrm{~S}_{1} \mathrm{~S}_{6}}$} & \multicolumn{3}{|l|}{ B4 } & \multicolumn{5}{|c|}{ B08 019} & \multicolumn{4}{|c|}{ BO5 O19 } & \\
\hline & & & $\mathrm{S}_{1} \mathrm{~s}_{1}$ & & & & $S_{1} S_{6}$ & $\mathrm{~S}_{6} \mathrm{~S}_{\mathrm{rec}}$ & & & & $\mathrm{S}_{1} \mathrm{~S}_{\mathrm{rec}}$ & $\mathrm{S}_{6} \mathrm{~S}_{\mathrm{rec}}$ & & \\
\hline $\begin{array}{l}\text { Prog. } \\
\text { (mat) }\end{array}$ & Self & $\begin{array}{l}\text { O19 } \\
\text { (pat) }\end{array}$ & $\begin{array}{l}\text { B4 } \\
\text { (pat) }\end{array}$ & $\begin{array}{l}\text { BO8 } \\
\text { (pat) }\end{array}$ & $S$ & Self & $\begin{array}{l}\text { O19 } \\
\text { (pat) }\end{array}$ & $\begin{array}{c}\text { B4 } \\
\text { (pat) }\end{array}$ & $\begin{array}{l}\text { BO8 } \\
\text { (pat) }\end{array}$ & $S$ & Self & $\begin{array}{l}\text { O19 } \\
\text { (pat) }\end{array}$ & $\begin{array}{c}\text { B4 } \\
\text { (pat) }\end{array}$ & $\begin{array}{l}\text { BO5 } \\
\text { (pat) }\end{array}$ & $S$ \\
\hline 1 & - & + & - & + & $S_{1}$ & - & $+/-$ & $+/-$ & - & $\mathrm{S}_{\mathrm{rec}}$ ? & - & + & - & - & $S_{1}$ \\
\hline 2 & - & + & - & $+/-$ & $\mathrm{S}_{1} ?$ & - & + & - & - & $S_{1}$ & - & - & + & + & $\mathrm{S}_{6}$ \\
\hline 3 & - & + & - & + & $S_{1}$ & - & $+/-$ & + & - & $\mathrm{S}_{6} ?$ & - & + & + & $+/-$ & $\mathrm{S}_{\mathrm{rec}}$ ? \\
\hline 4 & - & + & - & + & $\mathrm{S}_{1}$ & - & - & + & - & $\mathrm{S}_{6}$ & - & + & - & - & $S_{1}$ \\
\hline 5 & - & + & - & + & $S_{1}$ & - & + & - & + & $S_{1}$ & - & + & + & + & $\mathrm{S}_{\mathrm{rec}}$ \\
\hline 6 & - & - & + & - & $\mathrm{S}_{6}$ & - & + & + & - & $\mathrm{S}_{\mathrm{rec}}$ ? & - & - & - & - & $S_{1} S_{6}$ \\
\hline 7 & - & - & + & - & $\mathrm{S}_{6}$ & - & $+/-$ & - & + & $S_{1} ?$ & - & $+/-$ & + & + & $\mathrm{S}_{\mathrm{rec}}$ ? \\
\hline 8 & - & - & + & - & $\mathrm{S}_{6}$ & - & $+/-$ & + & - & $\mathrm{S}_{6} ?$ & - & + & - & - & $S_{1}$ \\
\hline 9 & - & + & - & - & $\mathrm{S}_{1} ?$ & - & $+/-$ & + & - & $\mathrm{S}_{6} ?$ & - & - & + & + & $\mathrm{S}_{6}$ \\
\hline 10 & & & & & & - & + & + & + & $\mathrm{S}_{\mathrm{rec}}$ & - & + & - & - & $S_{1}$ \\
\hline 11 & & & & & & - & - & + & $+/-$ & $\mathrm{S}_{6} ?$ & $+/-$ & + & $+/-$ & $+/-$ & $\mathrm{S}_{\mathrm{rec}}$ ? \\
\hline 12 & & & & & & - & - & - & - & $S_{1} S_{6}$ & - & $+/-$ & + & + & $\mathrm{S}_{\mathrm{rec}}$ ? \\
\hline $\begin{array}{c}\text { Prog. } \\
\text { (pat) }\end{array}$ & & $\begin{array}{c}\text { O19 } \\
\text { (mat) }\end{array}$ & $\begin{array}{c}\text { B4 } \\
\text { (mat) }\end{array}$ & $\begin{array}{l}\text { BO8 } \\
\text { (mat) }\end{array}$ & $S$ & & $\begin{array}{l}\mathrm{OS}_{1} 9 \\
\text { (mat) }\end{array}$ & $\begin{array}{c}\text { B4 } \\
\text { (mat) }\end{array}$ & $\begin{array}{l}\text { BO8 } \\
\text { (mat) }\end{array}$ & $S$ & & $\begin{array}{l}\mathrm{OS}_{1} 9 \\
\text { (mat) }\end{array}$ & $\begin{array}{c}\text { B4 } \\
\text { (mat) }\end{array}$ & $\begin{array}{c}\text { BO5 } \\
\text { (mat) }\end{array}$ & $S$ \\
\hline 1 & & + & - & + & $S_{1}$ & & + & + & - & $\mathrm{S}_{\mathrm{rec}}$ ? & & + & - & - & $S_{1}$ \\
\hline 2 & & + & - & + & $S_{1}$ & & + & - & + & $S_{1}$ & & $+/-$ & + & + & $\mathrm{S}_{6} ?$ \\
\hline 3 & & + & - & + & $S_{1}$ & & - & + & - & $S_{6}$ & & + & + & + & $\mathrm{S}_{\mathrm{rec}}$ \\
\hline 4 & & + & - & + & $S_{1}$ & & $+/-$ & - & - & $S_{1} S_{6}$ & & + & $+/-$ & $+/-$ & $\mathrm{S}_{1} ?$ \\
\hline 5 & & + & - & + & $S_{1}$ & & + & - & + & $S_{1}$ & & $+/-$ & $+/-$ & + & $\mathrm{S}_{\mathrm{rec}}$ ? \\
\hline 6 & & - & + & - & $\mathrm{S}_{6}$ & & + & - & - & $\mathrm{S}_{1} ?$ & & - & - & $+/-$ & $S_{1} S_{6}$ \\
\hline 7 & & - & + & - & $\mathrm{S}_{6}$ & & + & - & + & $S_{1}$ & & + & + & + & $\mathrm{S}_{\mathrm{rec}}$ \\
\hline 8 & & $+/-$ & + & - & $\mathrm{S}_{6} ?$ & & - & + & $+/-$ & $\mathrm{S}_{6} ?$ & & + & + & + & $\mathrm{S}_{\mathrm{rec}}$ \\
\hline 9 & & + & - & $+/-$ & $\mathrm{S}_{1} ?$ & & - & - & - & $S_{1} S_{6}$ & & $+/-$ & $+/-$ & + & $\mathrm{S}_{\mathrm{rec}} ?$ \\
\hline 10 & & & & & & & + & + & $+/-$ & $\mathrm{S}_{\mathrm{rec}}$ ? & & + & + & $+/-$ & $\mathrm{S}_{\mathrm{rec}}$ ? \\
\hline 11 & & & & & & & - & + & $+/-$ & $\mathrm{S}_{6} ?$ & & + & + & + & $\mathrm{S}_{\mathrm{rec}}$ \\
\hline 12 & & & & & & & - & - & - & $S_{1} S_{6}$ & & + & + & + & $\mathrm{S}_{\mathrm{rec}}$ \\
\hline
\end{tabular}

Figure 4 Self-incompatibility tests and backcross compatibility results for three Senecio squalidus progenies derived from backcrosses between a recessive S phenotype B4 $\times$ O19 progeny (BO8) and its B4 and O19 parents and an $\mathrm{S}_{1}$ phenotype $\mathrm{B} 4 \times \mathrm{O} 19$ progeny (BO5) and its O19 parent. The $S$ genotypes of BO8 and BO5 were subsequently identified as $S_{1} S_{6}$, and $S_{1} S_{r e c}$, on the basis of these backcross results respectively. Labels and diallels follow the same scheme as Figure 3.

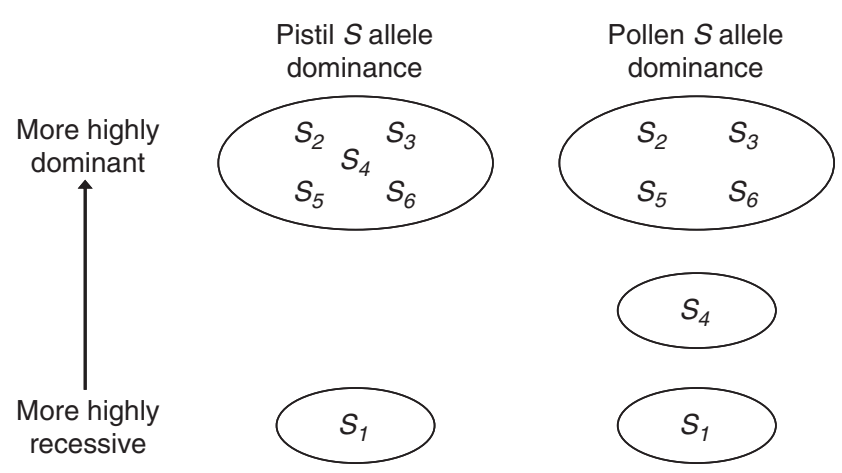

Figure 5 Dominance hierarchy of $S$ alleles observed in S. squalidus progenies. $S$ alleles have been placed into circled dominance classes on the basis of observed dominance interactions in progeny array crossing experiments. Different $S$ alleles were placed within the same $S$ allele class and assumed to be codominant when the $S$ alleles showed equivalent dominance interactions with $S$ alleles in other dominance classes. experiment, the anomalous cross-compatibilities could not be simply attributed to a weakening in the strength of expression of SI because most of these individuals remained strongly SI.

\section{Discussion}

\section{$S$ allele dominance interactions}

This analysis of $S$ allele dominance interactions in S. squalidus revealed an SSI system of considerable complexity in terms of dominance interactions despite the small number of $S$ alleles. Among the six $S$ alleles present in the Oxford $S$. squalidus population, at least two $S$ allele dominance classes were observed for $S$ allele interactions in pistil and at least three dominance classes were observed for $S$ alleles in pollen (Figure 5). Asymmetry in pollen-pistil $S$ allele interactions was also confirmed to be a feature of this small set of $S$ alleles, where $S_{4}$ and $S_{5}$ interact codominantly in pistil but $S_{5}$ is 
a

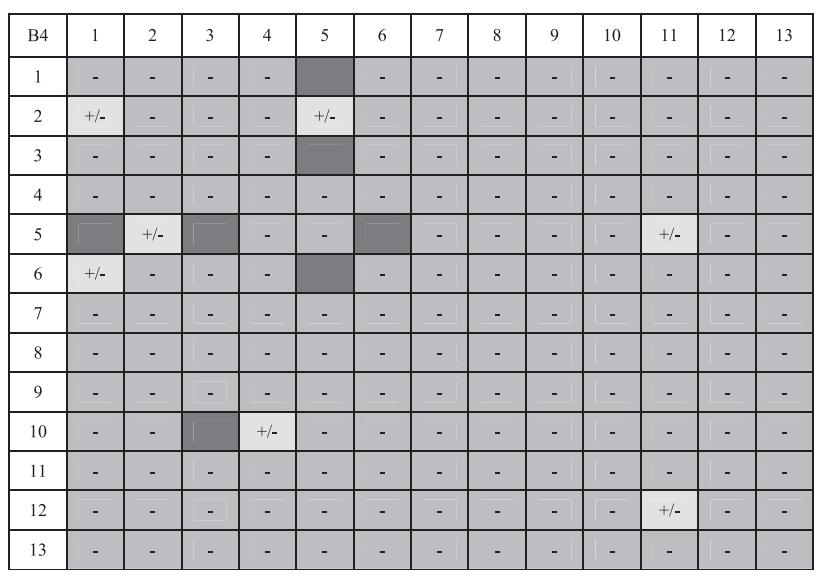

b

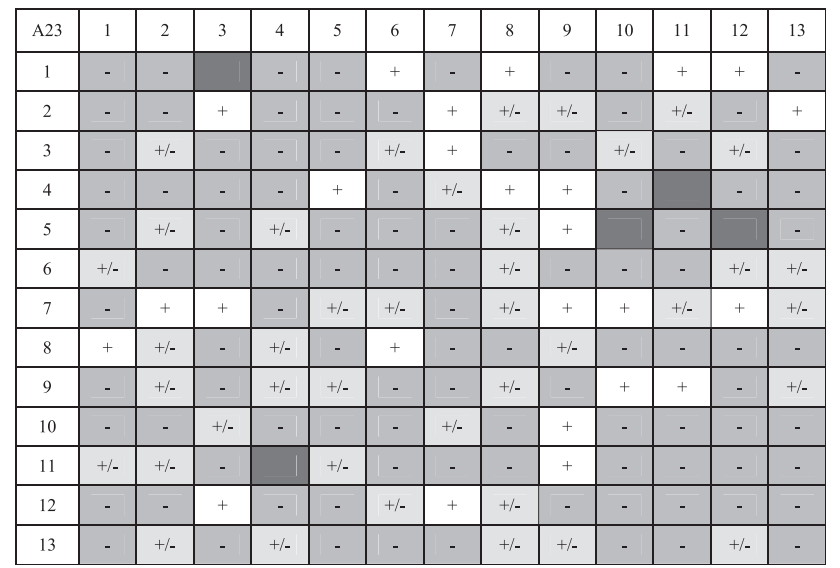

Figure 6 Mating table diallels for two third-generation selfed progeny arrays derived from $S_{1} S_{1}$ genotype (B4, panel a) and an $S_{6} S_{6}$ genotype (A23; panel b) individuals with different genetic backgrounds and self-incompatibility (SI) modifier expression. Plants are identified on the first row and column of the diallels. Maternal individuals are listed down the rows whereas paternal individuals are listed along the columns. Missing cross results are shaded dark grey. Symbols and shading of all other cross results are as described in Figure 3.

dominant to $S_{4}$ in pollen (Table 1; Figures 1 and 3). Thus, the SSI system of invasive $S$. squalidus preserves important $S$ allele features of multiple dominance classes and tissue-specific dominance interactions characteristic of SSI in other wild species.

The number of $S$ allele dominance classes was conservatively evaluated by grouping some $S$ alleles together into the most dominant class in the absence of direct genotype interaction data from progeny crosses. This method of grouping assumes that codominant interactions are the rule between $S$ alleles sharing the same dominance class. There is some supporting evidence for codominant interactions between some pairs of $S$ alleles in this dominance class. For instance, pistil-specific codominance has previously been observed between $S_{4}$ and $S_{6}$ based on diallel crosses of wild sampled individuals of an Oxford population (Brennan et al., 2002). The tissue-specific dominance interaction between $S_{4}$ and $S_{6}$ is identical to that observed for $S_{4}$ and $S_{5}$, which further supports the pollen-specific dominance class observed in this study. For another two $S$ alleles in this dominance class, variable dominance interactions, ranging from tissuespecific codominance to full codominance, have been identified in cross diallels of samples from other populations ( $S_{2}$ and $S_{3}$, Brennan et al., 2006) suggesting that dominance interactions between $S$ alleles may not be fixed between populations and could evolve under certain selective scenarios (Billiard et al., 2007). Such dominance 'flexibility' may be an important route to increasing mate availability when $S$ allele diversity is low, as in small or colonizing populations (Brennan et al., 2003).

Our grouping of $S$ alleles into dominance classes indicated that the most dominant dominance class comprised the majority of $S$ alleles, whereas the most recessive class consisted of a single $S$ allele, $S_{1}$, assuming no additional recessive $S$ alleles are still to be identified (Figure 5). This observation of increasing numbers of $S$ alleles with increasing dominance level is in accordance with both theoretical expectations (Schierup et al.,
1997; Schierup, 1998; Uyenoyama, 2000; Billiard et al., 2007) and empirical observations (Kowyama et al., 1994; Glemin et al., 2005; Prigoda et al., 2005; Schierup et al., 2006) for SSI systems with multiple $S$ allele dominance classes. This difference in $S$ allele diversity, dependant on the relative dominance level of individual $S$ alleles, is due to stronger negative frequency-dependent selection acting upon more dominant $S$ alleles because their $S$ phenotypes are more frequently expressed and exposed to selection in different $S$ genotype combinations than more recessive $S$ alleles. In finite, subdivided populations, stronger negative frequency-dependent selection acting on the more dominant $S$ alleles is more effective both at protecting $S$ allele frequencies from loss through genetic drift and at promoting enhanced migration between populations because novel dominant $S$ alleles are more likely to be expressed at low frequency than recessive $S$ alleles (Schierup et al., 1997; Schierup, 1998; Billiard et al., 2007). Thus, over evolutionary time stronger negative frequency-dependent selection will lead to the accumulation and retention of more $S$ alleles at more dominant classes relative to recessive $S$ alleles. Under certain conditions, such as tissue-specific $S$ allele dominance, these selective differences between $S$ alleles at different dominance levels can lead towards the continual evolution of increasing $S$ dominance (Schierup et al., 1997).

In this study, a single $S$ allele, $S_{1}$, was observed to occupy the most recessive dominance class in $S$. squalidus, assuming no more recessive $S$ alleles remain to be identified (Figure 5). Recessive $S$ alleles are expected to reach higher equilibrium frequencies than $S$ alleles from more dominant classes, because their presence is more often masked by dominant counterparts in different genotype combinations; a phenomenon known as the 'recessive effect' (Sampson, 1974). Furthermore, $S$ alleles within a given dominance class are selectively equivalent and so reach equal frequencies within classes (isoplethy; Sampson, 1974). Therefore, in cases where more dominant classes comprise more $S$ alleles, as observed here, the recessive effect is magnified and the difference in frequencies between 
recessive and dominant $S$ alleles is expected to be more extreme (Billiard et al., 2007). Indeed, simulations by Billiard et al. (2007) predict that for a range of SSI systems approximating that found for $S$. squalidus (that is, 3-7 alleles and 2-3 dominance classes) the most recessive allele is expected to be present at high frequencies $(0.41-0.67)$ and is often homozygous (0.15-0.41). At the level of $S$ phenotypes, all $S$ phenotypes are expected to be expressed equally frequently, but the most recessive $S$ phenotype class will consist entirely of $S$ homozygotes. Previous studies of $S$ phenotype frequencies in wild samples of $S$. squalidus found that the frequencies of different $S$ phenotype classes within populations tend to be largely similar (Brennan et al., 2002, 2006). It would be of interest to confirm through progeny crossing experiments whether the $S_{1}$ phenotype class consists exclusively of $S_{1}$ homozygotes and whether $S_{1}$ is a highly frequent recessive allele present but unexpressed in other $S$ phenotypes in wild $S$. squalidus populations.

\section{Modifiers of SI expression}

The crossing studies presented here also contribute to our understanding of the genetics and expression of modifiers of SI in S. squalidus previously described by Hiscock (2000) and Brennan et al. (2005). In particular, these data provide evidence for inherited $S$ modifiers in the O19 and A23 progeny lines (Figures 2, 4, and 6; Tables 1 and 2). These modifiers have two distinct influences on SI expression: increased self-compatibility $(\mathrm{B} 4 \times \mathrm{O} 19$ progeny and $\mathrm{BO} 5 \times \mathrm{O} 19$ backcross progeny; Figure 4), and increased cross-compatibility between related individuals $(\mathrm{B} 4 \times \mathrm{O} 19$ progeny, $\mathrm{BO} 5 \times \mathrm{O} 19$, $\mathrm{BO} 8 \times \mathrm{O} 19$ and $\mathrm{BO} 8 \times \mathrm{B} 4$ backcross progenies, and A23 self progeny; Tables 1 and 2; Figures 2, 4, and 6). The interpretation of $S$ allele genotypes and interactions was difficult for those progenies that expressed SI modifiers and detailed inferences about the genetics of these SI modifier phenotypes would require extensive further crossing experiments. For example, it would be interesting to investigate the $S$ phenotypes of additional larger $\mathrm{BO} \times \mathrm{O} 19$ and $\mathrm{BO} \times \mathrm{B} 4$ backcross progenies to compare with the three backcross progenies presented here. Despite that the two progeny lines (O19 and A23) with $S$ modifiers share the same $S$ allele $\left(S_{6}\right)$, the $S$ modifier or modifiers are probably not linked to the $S_{6}$ allele because progeny $S$ phenotypes indicate complex inheritance patterns and segregation independent of the $S$ locus (Table 2; Figures 4 and 6). However, it is interesting to speculate that the absence of $S$ modifiers in the B4 line that expresses the recessive $S_{1}$ allele could be due to reduced selection pressure to increase cross-compatibility relative to more dominant and frequently expressed $S$ alleles. The complex patterns of cross-compatibility indicate that $S$ modifiers confer considerable variability in SI expression, as has been observed previously for S. squalidus, and also frequently for other species that show a degree of mixed mating (Levin, 1996; Brennan et al., 2005). However, there is clearly also a genetic component to $S$ modifier expression, because anomalous compatible crossing behaviour was restricted to the $\mathrm{O} 19$ and A23 progeny lines, even when crosses within other progeny arrays were performed concurrently in the glasshouse.
A low frequency of selfing is frequently observed in otherwise SI and outcrossing species (reviewed by Levin, 1996; Vogler and Kalisz, 2001; Goodwillie et al., 2005), and for some model SI systems, a variety of loci and mechanisms responsible for selfing have been identified (reviewed by McClure et al., 2000). Although direct suppression of $S$ locus genes is sometimes the causal factor of SI breakdown, empirical evidence suggests that unlinked $S$-modifier loci that generate quantitative variation in SI expression are more often the rule (McClure et al., 2000). A theoretical understanding is emerging of the range of conditions under which mixed mating systems that combine SI and intermediate selfing rates are evolutionary stable (Vallejo-Marín and Uyenoyama, 2004; Porcher and Lande, 2005; Harder et al., 2007; Johnston et al., 2009). These conditions are the result of interplay between several factors including inbreeding depression and reproductive assurance. High levels of inbreeding depression have been observed in comparisons of fitness among cross- and self-progenies of S. squalidus: mean inbreeding depression coefficients ranging from 0.18 to 0.25 for different life history stages (Brennan et al., 2005). Such high levels of inbreeding depression probably limit the spread of $S$ modifiers that increase selfing rates. However, evidence suggests that reproductive assurance, which promotes the maintenance and spread of SI modifiers, is also an important factor affecting wild S. squalidus populations. Mate limitation is a feature of the SSI system of $S$. squalidus caused by the relatively few $S$ alleles present in this invasive species (7-11 $S$ alleles) that limits crosscompatibility (60.2-77.7\%) within sample diallels (Brennan et al., 2006). Mate limitation is further exacerbated by the presence of substantial pollen limitation in wild S. squalidus populations as measured from pollen addition experiments, which showed greater fruit-set in hand-pollinated capitula compared with open-pollinated capitula (Ludwig, Ortiz, Brennan and Hiscock, in preparation). Thus, the presence of $S$ modifiers that increase self- and cross-compatibility in the presence of an otherwise strongly expressed SSI system in S. squalidus is probably the result of a balance between selective forces that both favour and oppose reproduction through outcrossing.

Some of the $S$-modifier behaviour identified in this study increased cross-compatibility without increasing self-compatibility. In this regard, these $S$ modifiers behaved as a complementary SI system. Speculatively, this could be equivalent to the $G$ locus observed to be acting subordinately to the $S$ locus to increase crosscompatibility in some Brassicaceae and Asteraceae species (reviewed in Lewis, 1994). In these studies, the diallelic $G$ locus was hypothesized to be the remnant of an ancestral GSI system, which had been largely replaced by the SSI system conferring more effective control of matings between relatives (Lewis et al., 1988; Zuberi and Lewis, 1988; Lewis, 1994). It is also conceivable that in S. squalidus an SI modifier or modifiers that enhance cross-compatibility relative to single $S$ locus control are currently favoured as a component of a mating system that has undergone considerable perturbations subsequent to introduction and rapid spread within the UK. The $S$ and $Z$ loci that control SI in the Poaceae interact in a complementary manner to increase cross-compatibility levels greatly relative to that afforded by a single $S$ locus, 
thereby highlighting the advantages of a two-locus system if mates are limiting (Fearon et al., 1994). Phylogenetic analyses show that SI systems have evolved on numerous independent occasions (Igic and Kohn, 2001) and it also appears that SI systems can evolve at evolutionarily contemporary timescales, as indicated by the apparently recent transition from GSI to SSI within the genus Linanthus (Polemoniaceae; Goodwillie, 1999). The great diversity of documented SI systems indicates that selective pressure to promote outcrossing has clearly led to repeated, independent origins of SI systems and the co-option to SI of genes with different original functions (Hiscock and McInnis, 2003). From this point of view, it is important not to dismiss modifiers as simply the result of imperfect regulation of SI expression and to view regulation of selfing and outcrossing as a quantitative multi-locus trait rather than a purely qualitative single-locus trait.

\section{Conflict of interest}

The authors declare no conflict of interest.

\section{Acknowledgements}

We thank Bob and Andrew Hughes for technical support and for maintaining the plants. We also thank two anonymous reviewers for their constructive comments on an earlier draft of this paper. This work was funded by NERC and the Lady Emily Smyth Research Station (LESARS), University of Bristol.

\section{References}

Billiard S, Castric V, Vekemans X (2007). A general model to explore complex dominance patterns in plant sporophytic self-incompatibility systems. Genetics 175: 1351-1369.

Brennan AC, Harris SA, Hiscock SJ (2003). The population genetics of sporophytic self-incompatibility in Senecio squalidus L. (Asteraceae): avoidance of mating constraints imposed by low $S$ allele number. Phil Trans $R$ Soc London $B$ 358: 1047-1050.

Brennan AC, Harris SA, Hiscock SJ (2005). Modes and rates of selfing and associated inbreeding depression in the self-incompatible plant Senecio squalidus (Asteraceae): a successful colonizing species in the British Isles. New Phytol 168: $475-486$.

Brennan AC, Harris SA, Hiscock SJ (2006). The population genetics of sporophytic self-incompatibility in Senecio squalidus L. (Asteraceae): the number, frequency, and dominance interactions of $S$ alleles across its British range. Evolution 60: 213-224.

Brennan AC, Harris SA, Tabah DA, Hiscock SJ (2002). The population genetics of sporophytic self-incompatibility in Senecio squalidus L. (Asteraceae) I: $S$ allele diversity in a natural population. Heredity 89: 430-438.

Busch JW, Schoen DJ (2008). The evolution of self-incompatibility when mates are limiting. Trends Plant Sci 13: 128-136.

Fearon CH, Cornish MA, Haywood MD, Lawrence MJ (1994). Self-incompatibility in ryegrass $X$. Number and frequency of alleles in a natural population of Lolium perenne L. Heredity 73: 254-261.

Glemín S, Bataillon T, Ronfort J, Mignot A, Olivieri I (2001). Inbreeding depression in small populations of self-incompatible plants. Genetics 159: 1217-1229.

Glemin S, Gaude T, Guillemin M-L, Lourmas M, Olivieri I, Mignot A (2005). Balancing selection in the wild: testing population genetics theory of self-incompatibility in the rare species Brassica insularis. Genetics 171: 279-289.

Goodwillie C (1999). Multiple origins of self-incompatibility in Linanthus section Leptosiphon (Polemoniaceae): phylogenetic evidence from internal-transcribed-spacer sequence data. Evolution 53: 1387-1395.

Goodwillie C, Kalisz S, Eckert CG (2005). The evolutionary enigma of mixed mating systems in plants: occurrence, theoretical expectation and empirical evidence. Ann Rev Ecol Syst 36: 47-79.

Harder LD, Richards SA, Routley MB (2007). Effects of reproductive compensation, gamete discounting and reproductive assurance on mating-system diversity in hermaphrodites. Evolution 62: 157-172.

Hatakeyama K, Takasaki T, Suzuki G, Nishio T, Watanabe M, Isogai A et al. (2001). The $S$ receptor kinase gene determines dominance relationships of stigma expression in self-incompatibility in Brassica. Plant J 26: 69-76.

Hiscock SJ (2000). Genetic control of self-incompatibility in Senecio squalidus L. (Asteraceae): a successful colonizing species. Heredity 85: 10-19.

Hiscock SJ, McInnis SM (2003). The diversity of self-incompatibility systems in flowering plants. Plant Biol 5: 23-32.

Igic B, Kohn JR (2001). Evolutionary relationships among self-incompatibility RNases. Proc Natl Acad Sci USA 98: 13167-13171.

James JK, Abbott RJ (2005). Recent allopatric, homoploid hybrid speciation: the origin of Senecio squalidus (Asteraceae) in the British Isles from a hybrid zone on Mount Etna, Sicily. Evolution 59: 2533-2547.

Johnston MO, Porcher E, Cheptou P-O, Eckert CG, Elle E, Geber MA et al. 2009. Correlations among fertility components can maintain mixed mating in plants. Am Nat 173: 1-11.

Kowyama Y, Takahasi H, Muraoka K, Tani T, Hara K, Shiotani I (1994). Number, frequency and dominance relationships of $S$ alleles in diploid Ipomoea trifida. Heredity 73: 275-283.

Latta R (1994). Conditions favouring stable mixed mating systems with jointly evolving inbreeding depression. I Theor Biol 170: 15-23.

Levin DA (1996). The evolutionary significance of pseudoself-fertility. Am Nat 148: 321-332.

Lewis D (1994). Gametophytic-sporophytic incompatibility. In: Williams EG, Clarke AE, Knox RB (eds). Genetic Control of Self-incompatibility and Reproductive Development in Flowering Plants. Kluwer: Dordrecht, Germany.

Lewis D, Verma SC, Zuberi MI (1988). Gametophytic-sporophytic incompatibility in the Cruciferae, Raphanus satious. Heredity 61: 355-366.

McClure BA, Cruz-García F, Beecher B, Sulaman W (2000). Factors affecting inter- and intra-specific pollen rejection in Nicotiana. Ann Bot 85: 113-123.

Mehlenbacher SA (1997). Revised dominance hierarchy for S-alleles in Corylus avellana L. Theor Appl Genet 94: 360-366.

Ockendon DJ (1974). Distribution of self-incompatibility alleles and breeding structure of open pollinated cultivars of Brussels sprouts. Heredity 33: 159-171.

Pannell JR, Barrett SCH (1998). Baker's law revisited: reproductive assurance in a metapopulation. Evolution 52: 657-668.

Pannell JR, Dorken ME, Eppley SM (2005). 'Haldane's Sieve' in a metapopulation: sifting through plant reproductive polymorphisms. Trends Ecol Evol 20: 374-379.

Porcher E, Lande R (2005). The evolution of self-fertilization and inbreeding depression under pollen discounting and pollen limitation. J Evol Biol 18: 497-508.

Prigoda NL, Nassuth A, Mable BK (2005). Phenotypic and genotypic expression of self-incompatibility haplotypes in Arabidopsis lyrata suggests unique origin of alleles in different dominance classes. Mol Biol Evol 22: 1609-1620.

Sampson DR (1974). Equilibrium frequencies of sporophytic self-incompatibility alleles in Raphanus raphanistrum. Genetics 56: 241-251. 
Schierup MH (1998). The number of self-incompatibility alleles in a finite, subdivided population. Genetics 149: 1153-1162.

Schierup MH, Bechsgaard JS, Nielson LH, Christiansen FB (2006). Selection at work in self-incompatible Arabidopsis lyrata: mating patterns in a natural population. Genetics 172: 477-484.

Schierup MH, Vekemans X, Christiansen FB (1997). Evolutionary dynamics of self-incompatibility alleles in plants. Genetics 147: 835-846.

Shiba $H$, Iwano $M$, Entani $T$, Ishimoto $K$, Shimosato $H$, Che FS et al. (2002). The dominance of alleles controlling self-incompatibility in Brassica pollen is regulated at the RNA level. Plant Cell 14: 491-504.

Stone JL (2004). Sheltered load associated with $S$-alleles in Solanum carolinense. Heredity 92: 335-342.
Uyenoyama MK (2000). Evolutionary dynamics of selfincompatibility alleles in Brassica. Genetics 156: 351-359.

Vallejo-Marín M, Uyenoyama MK (2004). On the evolutionary costs of self-incompatibility: incomplete reproductive compensation due to pollen limitation. Evolution 58: 1924-1935.

Vekemans X, Schierup MH, Christiansen FB (1998). Mate availability and fecundity selection in multi-allelic self-incompatibility systems in plants. Evolution 52: 19-29.

Vogler DW, Kalisz S (2001). Sex among the flowers: the distribution of plant mating systems. Evolution 55: 202-204.

Vogler DW, Stephenson AG (2001). The potential for mixed mating in a self-incompatible plant. Int J Plant Sci 162: 801-805.

Zuberi MI, Lewis D (1988). Gametophytic-sporophytic incompatibility in the Cruciferae, Brassica campestris. Heredity 61: 367-377. 